\title{
Imaginación, subjetividad y compromiso: Sartre y las potencias de la ficción
}

\section{Imagination, subjectivity and commiment: Sartre and the fiction potencys}

\author{
Ignacio Quepons Ramírez \\ Universidad Veracruzana, México \\ ORCID: 0000-0002-1589-3951 \\ iquepons@uv.mx
}

\begin{abstract}
RESUMEN
Con base en una sistematización general de la fenomenología de lo imaginario de Sartre, el artículo propone las pautas para la reconstrucción de un concepto de ficción con base en las premisas de la filosofía de Sartre. Con ello, es posible aclarar la relación entre ficción y subjetividad y, por otro lado, sugerir una reflexión en torno a las potencias de la ficción que permita elucidar el sentido en el que puede comprenderse la noción sartreana de compromiso. En la primera parte, se presenta el papel de la imaginación y lo imaginario en los estudios literarios de Sartre. En la segunda parte, se presenta un esquema sobre la dialéctica de la reflexión y el papel de lo imaginario en la configuración de la subjetividad. Finalmente, y con base en la argumentación anterior, se plantea una interpretación fenomenológica del ensayo ¿Qué es literatura?, para sugerir inmediatamente después cómo la interpretación materialista de lo imaginario, sugerida por Sartre al final de sus días, se refiere a un concepto de ficción que se encuentra implícito en sus estudios literarios.
\end{abstract}


Palabras clave: Existencialismo; dialéctica; imaginario; fenomenología de la literatura; ficción.

\begin{abstract}
Departing from a general systematization of Sartre's phenomenology of the imaginary, the article proposes guidelines for the reconstruction of a concept of fiction based on the premises of Sartre's philosophy. With this, it is possible to clarify the relationship between fiction and subjectivity and, on the other hand, to suggest a reflection on the powers of fiction that allows us to elucidate the sense in which Sartre's notion of commitment can be understood. The first part presents the role of the imagination and the imaginary in Sartre's literary studies. The second part presents an outline of the dialectic of reflection and the role of the imaginary in the configuration of subjectivity. Finally, and based on the previous argumentation, a phenomenological interpretation of the essay What is Literature?, is proposed in order to suggest immediately afterwards how the materialist interpretation of the imaginary, suggested by Sartre at the end of his days, refers to a concept of fiction that is implicit in his literary studies.
\end{abstract}

Keywords: Existentialism; dialectics; imaginary; phenomenology of literature; fiction.

Si la literatura no es todo, no vale la pena perder en ella ni una hora. Si cada frase escrita no resuena en todos los niveles del hombre y de la sociedad, no significa nada.

Jean Paul Sartre

En las siguientes páginas, sugeriré las pautas para una aclaración de la noción implícita de ficción, en la intersección entre filosofía y literatura, en los escritos de Jean Paul Sartre. Para ello, tomaré como hilo conductor la centralidad, no siempre destacada, del tema de la imaginación en su obra filosófica y su aproximación al problema de la subjetividad en relación con la escritura literaria, siguiendo su ensayo ¿Qué es la literatura? 
En primer lugar, para Sartre (1997), de acuerdo con su estudio Lo imaginario, la imagen no es la representación de un objeto real, sino una forma de conciencia que consiste en la des-realización subjetiva de las relaciones constitutivas de la percepción, la cual produce un objeto "irreal": lo imaginario, como su correlato objetivo (p. 164). Así, lo decisivo de la potencia imaginaria de la subjetividad no es tanto la capacidad de proyectar representaciones, sino sobre todo minar las síntesis de regularidad por la cual se constituye el mundo perceptivo, incorporando la variación de sus posibilidades más allá de los meros hechos. De este modo, la conciencia de imagen introduce una singular forma de negatividad en el mundo (p. 240), toda vez que proyecta algo ausente o por completo inexistente como si estuviera presente; $y$ al hacerlo, destaca esa ausencia, esa nada, surgiendo desde el fondo de la realidad.

Por otra parte, la imaginación no sólo tiene el papel negativo de distorsionar las relaciones de regularidad del mundo objetivo; al ser expresión de una trascendencia, que rebasa lo meramente dado en la experiencia, propone una secuencia, un sentido, a favor de la compleción de la serie de apariciones que manifiesta, de forma parcial, un objeto en un campo fenoménico dado. La imaginación abre paso al espacio de consideración de lo que las cosas pueden ser más allá de lo que fácticamente son en un momento determinado; y esa posibilidad es abierta por la conciencia que la imagina. La imaginación, por tanto, es la prueba de que la subjetividad, comprendida como conciencia ante la cual el mundo de los hechos comparece, no se agota en la constatación de lo dado, sino que introduce lo negativo en la realidad como "aquello que falta" o que podría ser de otra forma: y eso es posible, según Sartre, porque los imaginantes son radicalmente libres. La imaginación es la expresión del carácter carencial y proyectivo del ente, que consiste en ser sus propias posibilidades: la existencia humana.

En este sentido, el discurso ficcional, particularmente en la narrativa, no podría ser comprendido, de acuerdo con el planteamiento sartreano, como una mera representación realista y vicaria de la realidad, sino como la expresión de una forma específica de "des-realización” de los hechos y proyección del sentido de lo que 
está por venir, que Sartre atribuye a la conciencia imaginante: la trascendencia de lo posible sobre la facticidad de los hechos. Sin embargo, a diferencia de la mera imaginación subjetiva, la ficción alcanza, gracias al lenguaje, una dimensión social, con efectos materiales sobre la configuración del mundo histórico.

Así, con base en un análisis orientado a hacer explícito el paralelismo entre la descripción sartreana de la conciencia de imagen y, en general, las claves de su noción de conciencia, y la fenomenología del lenguaje narrativo que subyace a su célebre ensayo ¿Qué es la literatura?, sugeriré cómo el proyecto de una consideración "materialista" de lo imaginario (Sartre, 1997), siguiendo la expresión de Sartre, deriva en la necesidad de dar consistencia a un concepto particular de ficción, desprendido de sus propias premisas.

De este modo, de acuerdo con una perspectiva sartreana, la ficción sería la dimensión del discurso que permite hacer explícita la actividad des-realizadora de la conciencia como una dimensión que opera en el mismo registro de la instancia por la cual nombramos el mundo: el lenguaje. Nombrar, designar, señalar el mundo, "usar el lenguaje", como dice Sartre, no quiere decir necesariamente "representar"; y esta es la clave para comprender el concepto implícito de ficción que subyace a su planteamiento filosófico.

Por otro lado, después de Sartre, como sugiere Pellejero (2007),

la evidencia del compromiso literario se torna una urgencia antes desconocida; después de Sartre el del compromiso pasa a ser un problema literario ineludible. Independientemente de la idea que nos hagamos sobre la literatura, ya no nos es posible pensar que el escritor escriba apenas para sí mismo. Y esto es Sartre quien lo plantea para nosotros de un modo casi fundacional (p. 143).

Con todo, y dejando de momento de lado los debates que tuvieron lugar especialmente en la década de los sesenta en torno al compromiso en la literatura, un momento previo, por lo menos en lo que concierne al estudio de Sartre, sería aclarar en dónde descansa la potencia política que atribuía a la literatura. Para tal fin, es preciso aclarar, en primer lugar, la relación entre la producción 
de ficciones y la estructura de la subjetividad. Sólo así es posible comprender por qué y cómo para Sartre la literatura es un llamamiento a hacerse cargo de la situación, es decir, a la libertad tanto de los que leen como los que no leen.

\section{LA Literatura TAL COMO SARTRE LA IMAGINÓ}

¿Qué es pues la literatura?, se preguntaba Sartre, ¿qué puede? La producción sartreana y la manera en como el escritor francés comprendía sus propios tránsitos entre diferentes registros de la escritura dificulta sobremanera una lectura integral de su pensamiento. Sin embargo, una clave decisiva, y no siempre atendida de forma explícita en los estudios de su obra, es la centralidad de su reflexión temprana sobre la imaginación y lo imaginario y sus resonancias a lo largo de su producción intelectual, todo el tiempo de la mano de la pregunta por lo que significa escribir. La pregunta por la aclaración del sentido de la escritura fue de la mano de una serie de estudios biográficos donde Sartre reconstruye, de acuerdo con diferentes métodos desarrollados en sus obras teóricas, la motivación existencial detrás de la elección por escribir. En esta línea se encuentran sus libros Baudelaire, San Genet comediante y martir, Mallarmé: la lucidez y su cara de sombra y su propia autobiografía novelada: Las palabras. El último proyecto dentro de esta serie, el cual condensa sus diferentes métodos, incluyendo su balance del marxismo en La crítica de la raźón dialéctica, es El idiota de la familia, obra en la cual Sartre (1975) realiza un estudio sobre la génesis de la personalidad de Flaubert y su decisión vital por la literatura. Sin embargo, ¿qué clase de estudios son estos libros? ¿Cómo deberíamos leerlos? A propósito de esta obra, en una de sus últimas entrevistas, en 1971, Sartre (1997) señala:

Desearía que mi estudio se leyera como una novela, porque, efectivamente, es la historia de un aprendizaje que conduce al fracaso de toda una vida. $\mathrm{Al}$ mismo tiempo que se lo leyera pensando que es la verdad, que es una novela verdadera (p. 12). 
Más adelante, agrega: "En el conjunto del libro aparece Flaubert tal como lo imagino, pero gracias a métodos que considero rigurosos creo que también aparece Flaubert tal y como es, tal como fue. En este estudio necesito constantemente la imaginación" (Sartre, 1997, p. 12). ¿A qué se refiere con su deseo de que su obra se lea como una novela y, sobre todo, como una novela verdadera? Una posible respuesta sería afirmar, sin más, que se trata de una narración. Sin embargo, cuando sugiere, inmediatamente después, que fue necesario el recurso de la imaginación, no quiere decir con ello, necesariamente, hacer afirmaciones falsas sobre Flaubert; por el contrario, la apelación a la imaginación descansa en ser la condición de posibilidad de la articulación de un discurso en torno a lo que se puede saber, en este caso, sobre Flaubert:

Para mí, como usted sabe, inteligencia, imaginación y sensibilidad son una y misma cosa que podría designar con el nombre de vivencia [vecú]. Estoy obligado a imaginar, si tomo por ejemplo una carta de 1838 y otra de 1852, que son documentos que nunca fueron relacionados ni por el propio Flaubert ni por sus corresponsales ni por los críticos. En ese momento tal relación no existía. Si yo la establezco es porque la imagino. Y una vez que la he imaginado, eso puede darme una relación real (Sartre, 1977, p. 12).

Con todo, es preciso comprender que el centro de la producción imaginaria -en este caso, la imagen de Flaubert "tal como fue"responde, al mismo tiempo, a premisas que Sartre sugiere como parte de la praxis constitutiva de la subjetividad de todos los escritores: la invención de sí mismos como una manera de ser-en-elmundo. Sin embargo, como el propio Sartre sugiere en la misma entrevista, el tema de la imaginación no es una novedad de su biografía de Flaubert, sino que se encuentra en sus primeros escritos de los años de mayor influencia de la fenomenología:

No presento la constitución de la persona como específica de Flaubert; se trata, más bien, de todos nosotros. Y la constitución consiste, en efecto, en crear una persona con roles, comportamientos esperados a partir de lo que llamo el ser constituido. En otras pala- 
bras, habría que hacer para todos -y también para personas muy activas- el trabajo que yo hice sobre Flaubert: mostrar la constitución y la personalización del individuo, es decir, el paso hacia lo concreto del condicionamiento abstracto por las estructuras familiares Es cierto que en Flaubert el elemento irreal es total: la diferencia entre Flaubert y otro -en que evidentemente no pueden dejar de aparecer elementos imaginarios- es que Flaubert quiso ser totalmente imaginario (Sartre, 1997, p. 16).

Más adelante agrega:

Usted sabe cómo concibo el yo; no he cambiado. Es un objeto que está ante nosotros. Es decir que el yo aparece a la reflexión cuando ésta unifica las conciencias reflexivas. Hay entonces un polo de la reflexión que denomino el yo, el yo trascendente, y que es un cuasi objeto. En lo que respecta a Flaubert, él quiso que su yo fuera imaginario (Sartre, 1997, p. 17).

Como he señalado al inicio, de acuerdo con los escritos tempranos de Sartre la imaginación no es una representación, sino una manera por la cual la conciencia se dirige al mundo, des-realizándolo; y al hacerlo, produce, como su correlato, un objeto "irreal", que llama lo imaginario. Entonces, la cuestión es aclarar en qué medida esto involucra un concepto de ficción que debe distinguirse de la imaginación, la cual, aunque comparte la estructura intencional de la conciencia imaginante, no se reduce a las representaciones psicológicas de un sujeto individual.

Así, como la imagen no es una representación vicaria de lo real, sino lo contrario, una unidad de des-realización, así la ficción, en este sentido, no podría comprenderse como "lo semejante a lo verdadero". La imaginación, hemos dicho, es la expresión de la irrupción de la negatividad en el mundo gracias a la subjetividad, es decir, la imagen introduce un ámbito que des-realiza los hechos de la percepción y, al mismo tiempo, forma su propio campo irreal, por el cual la conciencia pro-pone un objeto ante sí, que se ajusta a sus expectativas. De esta forma, la producción de la ficción supone la negación del orden existente, de suspender la validez de lo 
que la percepción entrega de forma fáctica a favor de sus meras posibilidades. Por lo tanto, la irrupción del discurso ficcional subvierte el campo de lo posible, en la medida en que lo posible es, en cierto modo, relativo al orden de lo real. La ficción se encuentra en el límite de lo posible, linda con lo imposible, toda vez que pone en entredicho la sobredeterminación anticipada de que puede ser fundada en lo que asumimos como real.

En cierto modo, todo el proyecto de Sartre consiste en mostrar el carácter trascendental y constituyente de la fuerza de lo negativo desde la subjetividad como el motor intrínseco de la formación del mundo, como un mundo determinado por un sentido humano; y la literatura no es sino una de las expresiones más radicales de dicha fuerza. Sin embargo, a contracorriente del entusiasmo nietzscheano hacia la ficcionalización total, para Sartre de lo que se trata en literatura es de "decir la verdad", esto es, no decir "cualquier cosa" o no decir nada, sino "decir algo", tomar partido, intervenir y contribuir a la redefinición de la situación fáctica a favor de algo por venir. Decir la verdad no sólo es enunciar proposiciones verdaderas, ni es algo inocente; tiene intención, es decir, es un acto comprometido, cuyo objeto es convocar a la libertad de los demás, llamarlos a hacerse cargo del presente: "el fundamento de la verdad es la libertad” (Sartre, 1997, p. 69). Así, el compromiso, al que alude Sartre de forma recurrente, no es la exigencia de exhibir o representar la realidad, sino, una vez más, de construir el espacio que permita "decir la verdad" y, al hacerlo, hacer patente la fragilidad de lo real al reincorporar la fuerza de lo negativo que permite trascender el ámbito de los hechos a favor de que el mundo sea de otra manera, de un tiempo por venir: "La escritura no puede ser crítica sin cuestionar el todo en ella: es su contenido. La aventura de la escritura, en cada escritor, cuestiona a los hombres. A los que leen y a los que no leen" (Sartre, 1973, p. 25).

\section{DiALÉCTICA DE LA REFLEXIÓN Y EL LUGAR DE LO IMAGINARIO}

EN LA CONFIGURACIÓN DE LA SUBJETIVIDAD

Un aspecto que permite evaluar la radicalidad del problema de la ficción en la obra de Sartre, en relación con el problema de la ver- 
dad, no es sólo la cuestión de decir la verdad sobre las cosas, sino sobre todo qué significa "decir la verdad acerca de uno mismo". Esto nos reconduce a analizar la estructura de la subjetividad como la instancia por la cual se manifiesta la realidad.

Para Sartre, el acceso fundamental a la realidad es, sin lugar a dudas, la conciencia. No obstante, la forma originaria en la que tiene lugar la apertura del mundo no es la tematización explícita de sus objetos, ni la tematización de sí misma, bajo la figura reflexiva de un "yo soy". De hecho, uno de los rasgos característicos de la obra de Sartre es que se niega a identificar la conciencia con "el yo" (Sartre, 2003). Si la conciencia, como instancia de comparecencia de lo que es, no se manifiesta originariamente de forma contemplativa, sino fundamentalmente afectiva y práctica, entregada a las cosas que revela, tampoco comparece ante sí misma a la manera de un objeto ante la mirada. Sin embargo, de acuerdo con su propio principio, toda conciencia de algo es, al mismo tiempo, conciencia no tética o posicional de sí misma, es decir, no se tiene a ella misma como un objeto ante sí. Eso no significa que no pueda volver de forma explícita sobre sí misma como objeto de la reflexión, lo cual sería absurdo, pues entonces no sería conciencia.

Sartre aborda el problema de la auto-comparecencia de sí ante uno mismo en diferentes escenarios, que encuentran su formulación sistemática en el apartado sobre la reflexión en El ser y la nada. En el capítulo sobre la reflexión, señala que existen dos modalidades de dicha actividad: la reflexión pura y la reflexión impura o cómplice (Sartre, 1998).

La reflexión pura entrega la unidad del flujo temporal de la conciencia en su completa indeterminación para sí misma; sólo es conciencia del decurso temporal y la unidad sintética de sus vivencias con sus respectivos correlatos. La conciencia está unificada en una síntesis temporal de carácter pre-reflexivo, apuntando a una ipseidad, respecto de la cual se reclama su proyecto en el futuro (Sartre, 1999 , p. 218). Por el contrario, la reflexión impura o reflexión cómplice cierra el flujo temporal en la figura de un objeto, el "yo", en el cual reclama su estabilidad en lo que se ha sido y se atribuye todos los estados y acciones de la conciencia. 
Para Sartre, en la medida en que la reflexión impura se niega a la comparecencia del mero flujo de la corriente de vida y exige un objeto para la reflexión, la conciencia o el ser-para-sí lo que en realidad hace es negarse a sí misma. Sartre llama "la mala fe" a esta conducta negativa, por la cual la existencia humana se toma por lo que no es (Sartre, 1999, p. 191), es decir, es la conducta por la cual la subjetividad oculta su propia indeterminación en el afán de presentar ante sí una instancia acabada, de forma que se confunda lo que ha sido, la facticidad de su existencia con lo que puede ser, su trascendencia (Sartre, 1999, p. 222).

Así, el "yo" producido por la reflexión impura se presenta como la imagen de uno mismo, a partir de la cual es posible "decir lo que uno es" como si se tratara de un hecho más, predecible y abarcable en todas sus determinaciones. El yo, por tanto, es un cuasi-objeto, virtual, cuya función es ocultar la actividad de la conciencia, que en realidad hace comparecer ante sí algo que no es un hecho y, en consecuencia, proyecta, aunque de forma velada, una reconfiguración ficcional del espectro de relaciones existentes a favor de algo no sólo posible, sino dado, en presencia (Sartre, 1999, p. 224).

Por tanto, la conciencia reflexiva impura no se detiene en el autocomparecer del flujo de vida ante sí misma, sino que avanza hasta presentar un objeto trascendente, como el "reflejo" de la conciencia reflexionante, produciendo su propio reflejo, con apoyo de la imaginación. Este recurso es exigido por la propia inquietud de la conciencia. Es por ella que todo lo que es se manifiesta y, en consecuencia, exige su propia comparecencia ante sí misma en los mismos términos, como algo acabado. Sin embargo, de acuerdo con su propio principio, la subjetividad se debate entre su propio fundamento y encontrar la razón de su ser más allá de sí misma, lo que equivale a negarse a sí misma: no ser libre. El último recurso frente a la angustia que ocasiona su propia indeterminación es proyectar un "reflejo" del reflejante de forma impura, inventar la ficción de que es su propio fundamento: una vida con un sentido otorgado a la manera de un destino. Así, la proyección imaginaria de sí no responde a otra motivación que la de otorgar a la vida la plenitud y coherencia, la necesidad que hace de los momentos vivi- 
dos las instancias de la realización de esto que "efectivamente soy". En la novela La náusea, presenta la cuestión de la siguiente forma:

para que el suceso más trivial se convierta en aventura es necesario y suficiente contarlo. Esto es lo que engaña a la gente; el hombre es siempre un narrador de historias; vive rodeado de sus historias y de las ajenas; ve a través de ellas lo que le sucede, y trata de vivir su vida como si la contara (Sartre, 1947, p. 52).

Lo cierto es que sólo al final de una vida es posible hacer ese recorrido y para entonces ya de nada vale, pues eso que somos ya no lo somos más. Sólo en ese momento y retrospectiva cabe hablar de algo así como un destino: cuando ya no importa. De modo que es preciso elegir, dice Sartre: "vivir o contar" (Sartre, 1947, p. 52). De tal forma, al final del día, los existentes humanos se debaten entre la asunción de la fragilidad de sus proyectos o la reducción de todo lo que pueden ser a la facticidad que son ahora. La imaginación, y con ella, la proyección imaginaria de sí, juega, por tanto, dos papeles importantes. En primer lugar, es la posibilidad de ser justo lo que no soy, sometiendo mi trascendencia a la imagen que reduce mi ser a mi facticidad, que la justifica. Sin embargo, al asumirse como "posibilidad" esta conducta está minada de raíz, pues en cualquier caso se afirma la libertad, aunque de forma implícita, como opción hacia una autodeterminación no reconocida como tal. En segundo lugar, el carácter constituyente de la imaginación como posibilidad de relanzar lo que soy en una trascendencia abierta de mis posibilidades, de modo que la imaginación se convierte, al mismo tiempo, en la forma de la imagen de sí y en una proyección de mí, en sentido literal: la configuración creativa de la vida como proyecto.

No obstante, la escritura permite una salida productiva a las paradojas del ocultamiento de uno mismo para sí mismo, que tiene lugar en la mala fe. La exteriorización de la constitución imaginaria de sí en la escritura da "cuerpo", por así decir, a la imagen. Pasa de ser un mero correlato fenoménico, y valer sólo para mí, a ser más allá de mí, como proyección de una imagen de sí que me singulariza y me trasciende. En la medida en que el sentido de la imagen se 
constituye ya no sólo en mí, sino en las determinaciones que proceden de la imagen, ahora constituida por los otros, los lectores, los efectos de esta ficción, están ciertamente fuera de mi control, pero apelan a un sentido de libertad, la de los otros, los que creen lo que les digo -o no-, los que "me eligen". Aquí cobra sus efectos productivos el fracaso de mi autodeterminación: soy más allá de mí porque, desde el principio, el yo está "afuera" de la conciencia (Sartre, 2003, p. 29) y esto implica que sus determinaciones son constituidas también por la comunidad de sujetos que me rodean y dicha determinación, sobre todo, es un sistema de acciones consecuentes, no reflexivas (Sartre, 2003, p. 110).

La escritura es, por tanto, una llamada a completar la historia, a reconocer la enunciación en una coherencia común, un pacto de complicidad que justifica tanto al que escribe como al que lee: no se escribe, piensa Sartre, para sí mismo, sino siempre para otros. El lector reconoce en las palabras del autor un mundo, como si lo escrito hubiera sido escrito para él, para su tiempo, que nunca es el tiempo de quien escribe. A propósito de esta cuestión, Sartre (1996) señala:

Se ha entendido 'Écrire pur son époque' como si ello significara: escribir para el propio presente. Pero no: es escribir para un porvenir concreto delimitado por las esperanzas, los temores y las posibilidades de acción de todos y cada uno (p. 67).

La escritura es proyecto. Se escribe siempre para un tiempo por venir. Y permite que ese espacio en el que puede "vivir" su propia trascendencia trascendida en el otro, que no sólo lo "mira", sino que lo "lee". Sartre (1950) remata su idea de la siguiente forma:

Escribir es, pues, a la vez revelar el mundo y proponerlo como una tarea a la generosidad del lector. Es recurrir a la conciencia del prójimo para hacerse reconocer como esencial a la totalidad del ser; es querer vivir esta esencialidad por personas interpuestas. Pero como, por otro lado, el mundo real sólo se revela en la acción, como no cabe sentirse en él, sino pasándolo para cambiarlo, el uni- 
verso del novelista crecería de espesor, si no se lo descubriera en un movimiento para trascenderlo (p. 85).

\section{DE VUELTA A LA LITERATURA: ¿QUÉ ES ESCRIBIR?}

Luego de haber aclarado la dinámica dialéctica entre imaginación y subjetividad, de acuerdo con algunos momentos clave del itinerario filosófico sartreano, volvamos al tema de la ficción literaria. En 1947, apenas concluida la Segunda Guerra Mundial, Sartre publica su ensayo intitulado ¿Qué es la literatura? El ensayo inicial comienza haciendo un balance del papel social del escritor en su tiempo y propone una reflexión en torno a la naturaleza del lenguaje en el contexto de la expresión literaria. En otro tiempo, dice Sartre, se tenía a los poetas como profetas y la literatura cumplía una función social. En cambio, un signo de la modernidad es que la emancipación de la ciencia y de las artes dio lugar a cierta idea del arte por el arte, que terminó por anular la literatura: según Sartre, la convierte en silencio.

De este modo, la modernidad se caracteriza por una crisis del lenguaje: "los literatos se habían resignado a ser únicamente ruiseñores." Y finalmente, hubo quienes llevaron la crisis más lejos, hasta el punto de no sólo publicar "un libro inútil", sino de sostener que "la finalidad secreta de toda literatura era la destrucción del lenguaje y para conseguirlo bastaba hablar para no decir nada" (Sartre, 1950, p. 9). Frente a este horizonte, Sartre anuncia su posicionamiento: "No queremos avergonzarnos de escribir y no tenemos ganas de hablar para no decir nada. Aunque quisiéramos, no podríamos hacerlo; nadie puede hacerlo. Todo escrito posee un sentido, aunque este sentido diste mucho del que el autor soñó dar a su trabajo" (Sartre, 1950, p. 9). Escribir, por tanto, compromete:

[El escritor] no tiene modo alguno de evadirse, queremos que se abrace estrechamente con su época, es su única oportunidad; su época está hecha para él y él está hecho para ella. [...]. Nosotros no queremos perder nada de nuestro tiempo; tal vez los hubo mejores, pero éste es el nuestro. No tenemos más que esta vida, tal vez esta revolución (Sartre, 1950, p. 10). 
Al final del primer texto, aparece la noción de literatura comprometida, que, dice, "no debe en modo alguno inducir a que se olvide la literatura y nuestra finalidad debe estribar en servir a la literatura, infundiéndole una sangre nueva, como en servir a la colectividad, tratando de darle a la literatura lo que le conviene" (Sartre, 1950, p. 24). ¿A qué conveniencia se refiere? La conveniencia de estar a la altura de su tiempo, de asumir un compromiso con el presente social, apostar, tomar partido de forma explícita:

reconozcamos que hay un aspecto de nuestros libros que se nos escapará para siempre. Un amor, una carrera, una revolución: he aquí otras tantas cosas que comenzamos ignorando su desenlace. ¿Por qué el escritor ha de escapar a la suerte común? Tiene que aceptar el arriesgarse, el perderse (Sartre, 1950, p. 40).

Más adelante, Sartre divide la cuestión en tres puntos: 1) ¿qué es escribir?, 2) ¿por qué se escribe? y 3) ¿para quién se escribe? Escribir es escribir sobre algo, por algo, para alguien. Sartre ataca la primera pregunta planteando el problema del significado y el recurso comunicativo de la prosa frente a otras manifestaciones artísticas, entre las que se incluye la poesía, pues al negarse el poeta a utilizar el lenguaje no trabaja, de acuerdo con el planteamiento de Sartre (1950), en sentido estricto, con "significados", pues no buscan "nombrar" algo. Nombrar "supone un perpetuo sacrificio del nombre al objeto nombrado, o hablando como Hegel, el nombre se revela como lo inesencial delante de la cosa, que es lo esencial" (p. 49). Por tanto, concluye Sartre, "los poetas no hablan, tampoco callan; es otra cosa" (p. 49). Pues el poeta toma las palabras como cosas y no como signos, corresponde al signo el carácter de poder atravesarlo como un índice "y perseguir más allá a la cosa significada o volver la vista hacia su realidad y considerarlo como objeto. El hombre que habla está más allá de las palabras, cerca del objeto; el poeta está más aquí’” (p. 49).

Por otro lado, la relación del que habla con las palabras es semejante con la experiencia del cuerpo: 
El que habla está situado en el lenguaje, cercado por las palabras; éstas son las prolongaciones de sus sentidos, sus pinzas, sus antenas, sus lentes; ese hombre las maneja desde dentro, las siente como siente su cuerpo, está rodeado de un cuerpo verbal, del que apenas tiene conciencia y que extiende su acción por el mundo (Sartre, 1950, p. 50).

Esta descripción es fundamental para destacar la relación esencial no sólo del pensamiento con el lenguaje, sino la implicación del lenguaje en nuestro ser-en-el-mundo. Deshacerse de este vínculo fundamental resulta en una abstracción semejante a la de desprenderse del cuerpo propio.

Así como el cuerpo propio se abre a la espacialidad originaria, donde se despliega la proximidad y la distancia de la situación espacial, el lenguaje configura el entorno de relaciones, ya próximas, ya distantes, de la existencia en el mundo. De alguna forma, el que habla no está vuelto sobre el lenguaje, como el poeta:

En lugar de conocer primeramente las cosas por sus nombres, parece que tiene primeramente un contacto silencioso con ellas, ya que, volviéndose hacia esta otra especie de cosas que son para él las palabras, tocándolas, palpándolas, descubre en ellas una pequeña luminosidad propia y afinidades particulares con la tierra, el cielo, el agua y todas las cosas creadas. Incapaz de servirse de la palabra como signo de un aspecto del mundo, ve en ella la imagen de uno de estos aspectos (Sartre, 1950, p. 50).

El que habla, quien escribe, está dirigido, a través de sus palabras, al mundo que su conciencia revela. Así, de acuerdo con Sartre, la poesía supone la comparecencia del lenguaje como algo ante la mirada, como el resto de las cosas, como un objeto de contemplación, frente al que escribe en prosa, al que habla, dice Sartre, que se sirve del lenguaje como se sirve de su cuerpo.

Estamos en el lenguaje como en nuestro cuerpo; lo sentimos espontáneamente al pasarlo, cuando nos dirigimos a otros fines, como sentimos nuestras manos y nuestros pies. Cuando lo emplea otro, lo percibimos como percibimos los miembros de los demás. 
Hay la palabra vivido y la palabra encontrado. Pero en los dos casos, es durante alguna empresa, sea de mí sobre los otros o de los otros sobre mí. La palabra es cierto momento determinado de la acción y no se comprende fuera de ella (Sartre, 1950, p. 55).

Lo interesante es que, quizá por la misma razón, no seamos capaces de volvernos hacia el lenguaje si no es, precisamente, por efecto de la irrupción de esa forma, que hace de éste un objeto, la poesía, despojando las palabras de su mera relación instrumental, tal y como los pintores se sirven de las figuras y los colores para dar forma a un discurso pictórico. Así, dice Sartre (1950) más adelante:

El prosista escribe, es verdad, y el poeta escribe también. Pero entre los dos actos de escribir no hay de común más que el movimiento de la mano que traza las letras. En lo demás, sus universos no tienen comunicación entre sí y lo que vale para el uno no vale para el otro. La prosa es utilitaria por esencia: definiría muy a gusto al prosista como hombre que se sirve de las palabras (p. 54).

Es preciso ver la descripción que Sartre hace de la escritura en prosa, en la misma clave que describe la conciencia pre-reflexiva, fundamentalmente práctica, que constituye la apertura originaria del mundo en sus obras fenomenológicas.

Por otra parte, si se considera únicamente esta estructura secundaria de la empresa que es el momento verbal, el grave error de los estilistas puros estriba en creer que el vocablo es un céfiro que discurre levemente por la superficie de las cosas, que las toca suavemente, sin alterarlas. Y que el hablante es un puro testigo que resume en una palabra su contemplación inofensiva. Hablar es actuar: toda cosa que se nombra ya no es completamente la misma; ha perdido su inocencia (Sartre, 1950, p. 56).

Lo mismo vale para el silencio, que tiene su propio vínculo significativo:

Es un momento del lenguaje; callarse no es quedarse mudo, sino negarse a hablar, es decir, hablar todavía. Por tanto, si un escritor ha optado por callarse en relación con un aspecto cualquiera del mundo o, según una expresión que dice muy bien lo que quiere 
decir, por pasarlo en silencio, hay derecho a formularle una tercera pregunta: ¿por qué hablas de esto antes de aquello y, ya que tú hablas para cambiar, por qué quieres cambiar esto antes de aquello? (Sartre, 1950, p. 58).

Por lo tanto, el punto de Sartre no es concentrar todo en la intención del autor, sino hacer ver que escribir, incluso más allá de nuestras intenciones, nos compromete, como compromete abrir los ojos, destacar con la mirada un sector de la realidad, convirtiendo al resto de los objetos en un fondo no atendido. El compromiso significa asumir una perspectiva activa sobre la condición de la que, de origen, no podemos escapar. No es que el escritor se vuelva comprometido; es que escribir compromete, lo queramos o no. El momento de la decisión es un asumir antes que un optar por una cosa o la otra. Sartre, por otro lado, tampoco está sugiriendo ninguna orientación explícita de hacia dónde debiera dirigirse ese compromiso: elegimos, según sus propias palabras, sin apelación.

El escritor debe comprometerse por completo en sus obras y no proceder con una pasividad abyecta, exponiendo sus vicios, sus desdichas y sus debilidades, sino con una voluntad decidida y con una elección, como una empresa total de vivir que somos cada uno (Sartre, 1950, p. 65).

La segunda cuestión es ¿por qué se escribe? La pregunta está dirigida a las motivaciones y, en consecuencia, a la decisión: por qué precisamente escribir. Sartre juega, en su terreno, la elucidación de la elección: la actividad de escribir conduce precisamente al reclamo de que los escritores se comprometan. El planteamiento retoma las tesis fenomenológicas que son comunes a otras obras, a saber, que toda conciencia -o lo que en su lenguaje llama "el ser para sî"- no sólo se define por ser conciencia de algo, sino que es, al mismo tiempo, conciencia pre-reflexiva de sí.

Cada una de nuestras percepciones va acompañada de la conciencia de que la realidad humana es "reveladora", es decir, el medio por el que las cosas se manifiestan; es nuestra presencia en el mundo lo que multiplica las relaciones; somos nosotros los que ponemos en relación este árbol con este trozo de cielo; gracias 
a nosotros, esa estrella, muerta hace milenios, ese cuarto de luna y ese río se revelan en la unidad de un paisaje; es la velocidad de nuestro automóvil o nuestro avión lo que organiza las grandes masas terrestres; con cada uno de nuestros actos el mundo nos revela un nuevo rostro (Sartre, 1950, p. 69).

Sin embargo, la conciencia o ser-para-sí, como existencia individual, es inesencial en relación con el mundo que descubre; el paisaje al que damos la espalda será otra vez paisaje para otra conciencia que venga a revelarlo como tal; no depende precisamente de nosotros, sino de cualquier conciencia, no precisamente de la nuestra. Así, uno de los principales motivos de la creación artística, sostiene Sartre (1950), es una necesidad:

sentirnos esenciales en relación con el mundo. Este aspecto de los campos o del mar y esta expresión del rostro por mí revelados, cuando los fijo en una tela o un escrito, estrechando las relaciones, introduciendo el orden donde no lo había, tienen para mi conciencia el valor de una producción, es decir, hacen que me sienta esencial en relación con mi creación (p. 70).

No obstante, no puedo revelar y al mismo tiempo producir: "El objeto creado no se impone jamás" (Sartre, 1950, p. 70). Casi quisiéramos que el objeto creado nos sorprendiera, como si fuera creado por otro y se nos impusiera como un hecho, pero que, al mismo tiempo, nos uniera al objeto, de acuerdo con un vínculo de necesidad: que fuera precisamente para nosotros o, dicho de otro modo, que fuera nuestro destino, como conciencia individual, ser la instancia de manifestación de ese objeto, su condición necesaria.

Este es el tema que aparece en El ser y la nada, en torno a la dialéctica de la reflexión, como sugerimos antes, y Sartre (1950) establece la analogía entre la estructura de la subjetividad en relación con la aparición progresiva de los objetos de la percepción a lo largo del tiempo y el acto de escribir cuando afirma:

El objeto literario es un trompo extraño que sólo existe en movimiento. Para que surja hace falta un acto concreto que se denomina la lectura y, por otro lado, sólo dura lo que la lectura dure. Fuera 
de esto, no hay más que trazos negros sobre el papel. Ahora bien, el escritor no puede leer lo que escribe, mientras que el zapatero puede usar los zapatos que acaba de hacer, si son de su número, y el arquitecto puede vivir en la casa que ha construido. Al leer, se prevé, se está a la espera. Se prevé el final de la frase, la frase siguiente, la siguiente página; se espera que se confirmen o se desmientan las previsiones; la lectura se compone de una multitud de hipótesis, de sueños, y despertares, de esperanzas y decepciones; los lectores se hallan siempre más delante de la frase que lee, en un provenir solamente probable que se derrumba en parte y se consolida en otra parte a medida que se avanza, en un porvenir que retrocede de página a página y forma el horizonte móvil del objeto literario. Sin espera, sin porvenir, sin ignorancia, no hay objetividad (Sartre, 1950, p. 70).

El objeto, de alguna manera, siempre sorprende y siempre se proyecta o anticipa, de acuerdo con una pauta por cumplirse, que no se conoce de antemano. Y precisamente, en esta "ignorancia" relativa a lo objetivo reclama su realidad sobre la conciencia. En cambio, el que escribe supone una "cuasi-lectura implícita que hace la verdadera lectura imposible” (Sartre, 1950, p. 71), es decir, produce lo que en El ser y la nada llama una "reflexión impura". Más adelante agrega:

cuando las palabras se forman bajo la pluma, el autor las ve, sin duda, pero no las ve como el lector, pues las conoce antes de escribirlas; su mirada no tiene por función despertar rozándolas palabras dormidas que están a la espera de ser leídas, sino de controlar el trazado de los signos; es una misión puramente reguladora, en suma, y la vista nada enseña en este caso, salvo los menudos errores de la mano (p. 71).

La cuestión es que, a diferencia de quien lee, el escritor a cada paso, donde produce su obra, sólo se ve a sí mismo, se reconoce a sí mismo; su propia obra no lo sorprende. Esto no quiere decir, naturalmente, que uno escriba "para sí mismo"; este, dice Sartre (1950), sería "el mayor de los fracasos": 
El acto creador no es más que un momento incompleto y abstracto de la producción de una obra; si el autor fuera el único hombre existente, por mucho que escribiera, jamás su obra vería la luz como objeto; no habría más remedio que dejar la pluma o desesperarse. Pero la operación de escribir supone la de leer como su correlativo dialéctico y estos dos actos conexos necesitan agentes distintos. Lo que hará surgir ese objeto concreto e imaginario que es la obra [...] será el esfuerzo conjugado del autor y del lector. Sólo hay arte por y para los demás (p. 72).

Por otra parte, el objeto literario guarda una relación paradójica con el lenguaje, toda vez que, como parece sugerir Sartre (1950), no se agota en lo dicho, en lo escrito, sino en una posibilidad abierta, indeterminada, $\mathrm{y}$ siempre por venir:

El objeto literario, aunque se realice a través del lenguaje, no se halla jamás en el lenguaje; es al contrario, por naturaleza, silencio e impugnación de la palabra. Así, las cien mil palabras de un libro pueden ser leídas una a una sin que surja el sentido de la obra; el sentido no es la suma de las palabras, sino la totalidad orgánica de las mismas (p. 73).

Todo esto da lugar a una centralidad de la lectura en la constitución del objeto literario como tal. La eventual culminación o, en lenguaje fenomenológico, el cumplimiento de la intención del autor no es sólo el cierre del círculo de comunicación, sino la respuesta a una llamada, al comienzo absoluto que empieza con la lectura, donde la obra ejerce sus potencias más allá, incluso, de las expectativas del autor.

Ya que la creación no puede realizarse sin la lectura, ya que el artista debe confiar a otro el cuidado de terminar lo comenzado, ya que un autor puede percibirse esencial a su obra únicamente a través de la conciencia del lector, toda obra literaria es un llamamiento. Escribir es pedir al lector que haga pasar a la existencia objetiva la revelación que yo he emprendido por medio del lenguaje. Y si se pregunta a qué hace llamamiento el escritor, la respuesta es sencilla. Como no se encuentra nunca en el libro la razón suficiente para 
que el objeto estético se manifieste, sino solamente requerimientos para que el mismo sea producido, y como tampoco hay motivo bastante en el espíritu del autor, y su subjetividad, de la que no puede salir, no puede explicar el paso a la objetividad: la aparición de una obra de arte es un acontecimiento nuevo, que no podría explicarse con los datos anteriores. Y pues esta creación dirigida es un comienzo absoluto, ha de ser realizada por la libertad del lector, en lo que esta libertad tiene de más duro. Así, el escritor recurre a la libertad del lector para que ella colabore a la producción de la obra (Sartre, 1950).

De este modo, aunque el escritor "usa el lenguaje", el libro no es un mero instrumento. El instrumento no reclama mi libertad, más bien me sirvo del instrumento para tales o cuales fines, es decir, un libro no "sirve a mi libertad: la requiere" (Sartre, 1950, p. 75). Escribir, por tanto, es apelar a la libertad, "en nombre de ella misma, es decir, en nombre de la confianza que se le otorga" (p. 75). El libro no es un utensilio, sino que su propia efectuación "propone como fin la libertad de lector" (p. 76).

Así, la escritura es una suerte de materialización de la imaginación, toda vez que no identifiquemos la imagen producida con una representación, sino con una forma de estar dirigida a la existencia fuera de sí, haciendo patente, y al mismo tiempo negando, el mundo: la ficción. En esa misma medida, el sentido del lenguaje no es una cosa, ni una mera representación, como una imagen mental, sino que apela a una especie de perspectiva pragmática acerca del significado: el significado de las palabras remite a una intención, pero una intención cuyo origen no es la mera representación, sino el proyecto práctico, sus consecuencias, con respecto a una situación dada. Esto tiene dos derivas interesantes: de un lado, escribir es una forma de elegir, de comprometerse con el mundo, con la situación -incluso, constituirse a uno mismo como escritor tiene su asunto-; por otro lado, la escritura es, al mismo tiempo, una llamada a la libertad de los lectores y una huida de una situación presumiblemente insoportable, donde el elemento de trascendencia negativa, propio de la conciencia, permite comprender a cabalidad su sentido. $Y$ eso nos devuelve al problema de la ficción, de acuerdo con lo que esboza- 
mos arriba. Así, como sugiere Borosi (2001), de acuerdo con Sartre, la eficacia de la literatura, sus potencias, descansan en la apuesta por "conducir al lector hacia una complicidad no inocente con el escritor" (p. 119). Sin embargo, dicha complicidad no quiere decir sumisión irrestricta; por el contrario, la eventualidad de un abierto rechazo de la obra es signo de que el lector ha tomado partido, se compromete. Por lo pronto, eso que Sartre llama la perspectiva materialista de la imaginación da la pauta a la necesidad de construir un concepto de ficción con base en sus propias premisas, a saber, con base en nuestra relación con el lenguaje como el cuerpo en el que se abre la situación, que permite esta ambigüedad de tornarse ficción y variar las posibilidades de la realidad: lo que ocurre en el registro psicológico como imaginario, en la escritura se torna algo real efectivo, más allá de la ensoñación del que imagina en solitario. La enunciación de las palabras constituye un acontecimiento real, con consecuencias más allá de sus propias expectativas.

\section{DE LA CONCIENCIA IMAGINANTE A LAS POTENCIAS DE LA FICCIÓN}

La diferencia entre imaginación y ficción, hemos sugerido, consiste en que el primero es un fenómeno descrito por Sartre en términos psicológicos, aunque él mismo sugiere, como he señalado antes, la necesidad de ampliar esta noción desde una perspectiva materialista. En cambio, ficción corresponde a un cierto registro del discurso. Las críticas de Sartre a la idea de lo imaginario y, en general, de la imagen como un discurso acerca de lo que no es, aunque guarda una cierta proximidad con lo que es, vale para la comprensión del concepto de ficción. Sartre denuncia, en La imaginación, la tradición que comprende a la imagen como una cosa y como objeto vicario de lo real, a favor de comprender la imaginación como una forma de conciencia, es decir, de relación con la realidad que no sólo remite a la experiencia, sino a acciones sobre la realidad.

La relación entre imaginación y ficción no sólo consiste en que la imaginación hace posible la ficción, o que la ficción motiva la imaginación, sino que las actividades de la conciencia que intervienen en la constitución de los imaginarios operan también en la ficción, sin una alusión inmediata a la dinámica psicológica de 
la producción de obras literarias. Por eso, es preciso insistir en la figura del lector en la producción de la ficción.

En un pasaje de su novela Blanco nocturno, el escritor argentino Ricardo Piglia sugiere una acepción de lo imaginario, en línea de comprender este ámbito no como algo vicario de la realidad, como su representación o como negación de la realidad, sino en relación con la apertura de lo posible: la zona de variación entre lo que existe y lo que no existe, cuya instancia material sería, de acuerdo con lo que hemos querido sugerir aquí, la ficción:

Lo acusaban de ser irreal, de no tener los pies en la tierra. Pero había estado pensando, lo imaginario no era lo irreal. Lo imaginario era lo posible, lo que todavía no es, y en esa proyección al futuro estaba, al mismo tiempo, lo que existe y lo que no existe. Esos dos polos se intercambiaban continuamente. Y lo imaginario es ese intercambio (Piglia, 2010, p. 232).

Así, diríamos con Sartre que la expresión material de ese espacio de intercambios, "lo imaginario", es precisamente la ficción, comprendida como campo de resolución y de batalla por la lucha de la apropiación de la circunstancia, a través del lenguaje, entre lo que existe y lo que está por venir. En este mismo sentido, la verdad no necesariamente es lo opuesto a la ficción. La verdad, para Sartre, coincide con una elección del presente, sin apelación, y decir la verdad no es sólo realizar enunciados verdaderos, sino convocar a la libertad de los otros para realizarlos o interpelarlos. Como sugiere Pellejero (2007), "El llamado de la literatura no es a los partidos, las naciones o a las clases, ni siquiera a los hombres en tanto sujetos constituidos sino a la potencial libertad de sus lectores" (p. 161). Así, en la medida en que la escritura apela a la libertad de los lectores, sin la cual simplemente no tiene sentido, Sartre cree que tiene una vocación tan disruptiva como democrática y, en consecuencia, no sólo enuncia la verdad como libre apropiación del presente, sino que hace posible las condiciones para que la verdad sea dicha. 


\section{BiBLIOGRAFÍA}

Borosi, S. (2001). Sobre ¿Qué es la literatura?: el compromiso y la ausencia de compromiso. En C. Tognonato, F. Ferrarotti, B. Romano, G. Farina, O. Pompeo, J. Simont, S. Briosi, E. Caldieri, P. Tomassia, G. Baratta, S. Teroni, P. Verstraeten y J. Colombel (Eds.), Sartre contra Sartre (pp. 113-120). Buenos Aires: Eds. del Signo.

Pellejero, E. (2007) ¿Qué es la literatura? Del compromiso sartreano a la fábula deleuziana. Devenires. Revista de Filosofía y Filosofía de la Cultura, 8(15), 155-177. <https://devenires.umich.mx/ devenires/index.php/devenires/article/view/552>.

Piglia, R. (2010). Blanco nocturno. Barcelona: Anagrama.

SARTre, J. P. (1947). La náusea. Buenos Aires: Losada.

Sartre, J. p. (1975). El idiota de la familia, 1-2. Buenos Aires: Ed. Tiempo Contemporáneo.

SARtre, J. P. (1997). Lo imaginario. (Trad. de M. Lamana). Buenos Aires: Losada.

Sartre, J. P. (1998). El ser y la nada. (Trad. de J. Valmar). Buenos Aires: Losada.

Sartre, J. P. (2003). La trascendencia del Ego. (Trad. de M. García-Baró). Madrid: Ed. Síntesis. 